\title{
Left Ventricular Rupture during Balloon Mitral Valvuloplasty
}

\author{
${ }^{1}$ Tazeen Sarguroh, ${ }^{2}$ Dipti Kotwani, ${ }^{3}$ Shakuntala Basantwani, ${ }^{4}$ Bharati Tendolkar
}

\begin{abstract}
Balloon mitral valvuloplasty (BMV) is a viable alternative to valve replacement surgery in patients with mitral stenosis. One of the rare complications of the procedure requiring immediate resuscitation and surgical repair is cardiac tamponade due to ventricular rupture. We report the anesthetic management of a 38 year old female with hemopericardium during BMV due to left ventricular rupture.
\end{abstract}

Keywords: BMV, Capnography, Electrocardiogram, Left ventricular rupture.

How to cite this article: Sarguroh T, Kotwani D, Basantwani S, Tendolkar B. Left Ventricular Rupture during Balloon Mitral Valvuloplasty. Res Inno Anaesth 2016;1(1):28-29.

Source of support: Nil

Conflict of interest: None

\section{INTRODUCTION}

Mitral stenosis is almost always due to fusion of the mitral valve leaflets at the commissure during the healing process of acute rheumatic fever. Since the initial description of balloon mitral valvuloplasty (BMV), the technique has become widely accepted as a viable alternative to surgery for rheumatic mitral stenosis. The occurrence of hemopericardium as a complication is between 1 and $3 \%$, and most of these procedures are done with anesthesia standby or with mild sedation. We here present a case of cardiac tamponade due to left ventricular rupture during BMV in a patient with severe rheumatic mitral stenosis and who was successfully managed and discharged post the complication.

\section{CASE REPORT}

A 38-year-old female weighing $45 \mathrm{~kg}$ with a diagnosis of rheumatic heart disease with severe mitral stenosis since 5 years was posted for balloon mitral valvuloplasty (BMV) with anesthesia standby. Patient was found to

\footnotetext{
${ }^{1}$ Senior Medical Officer, ${ }^{2}$ Assistant Professor, ${ }^{3}$ Associate Professor, ${ }^{4} \mathrm{Head}$

${ }^{1}$ Department of Anaesthesia, HBTMC and Dr RN Cooper Hospital, Mumbai, Maharashtra, India

${ }^{2-4}$ Department of Anaesthesia, LTMMC and LTMG Hospital Mumbai, Maharashtra, India
}

Corresponding Author: Tazeen Sarguroh, Senior Medical Officer, Department of Anaesthesia, HBTMC and Dr RN Cooper Hospital, Vile Parle, Mumbai, Maharashtra, India Phone: +919833247466, e-mail: tazeen.sarguroh@gmail.com have a loud first heart sound and a mid diastolic murmur on examination. Her electrocardiogram showed right axis deviation with excessive overload of left atrium and two-dimensional (2D) echo showed severe mitral stenosis with a mitral valve area of $0.8 \mathrm{~cm}^{2}$, mild mitral regurgitation (MR), moderate tricuspid regurgitation, severe pulmonary arterial hypertension with good biventricular function. Her routine blood investigations were within normal limits and she was on tab Digoxin $0.25 \mathrm{mg}$ OD, tab Aten $25 \mathrm{mg}$ OD, and tab Furosemide.

During the procedure, the patient developed suddenonset hemodynamic collapse with drowsiness post the trans-atrial puncture. Her pulse rate went up to $120 \mathrm{bpm}$ and blood pressure had fallen to $60 / 30 \mathrm{~mm} \mathrm{Hg}$. The procedure room $2 \mathrm{D}$ echo showed evidence of cardiac tamponade.

The patient had a 20G intravenous (IV) access before the procedure, and a femoral venous and arterial access was acquired for the procedure. Resuscitation in the catheterization lab was done by securing a 7 French catheter in the right internal jugular vein. Patient was intubated after induction with $0.2 \mathrm{mg} / \mathrm{kg}$ of etomidate. A pigtail catheter was inserted into the pericardium by cardiologists and autohemoperfusion was started. Patient was also started on inotropic support with dopamine at $10 \mathrm{U} / \mathrm{kg}$ and adrenaline at $0.6 \mathrm{U} / \mathrm{kg}$. Patient was shifted to the operation theater (OT) with inotropic support and continued autohemoperfusion.

In the OT after establishing electrocardiogram, pulse oximetry, invasive and noninvasive blood pressure monitoring along with capnography and temperature using the nasal probe, the patient was given a nondepolarizing muscle relaxant, vecuronium, in a dose of $0.1 \mathrm{mg} /$ $\mathrm{kg}$. Inotropic support was continued with dopamine at $8 \mathrm{U} / \mathrm{kg} / \mathrm{min}$ and adrenaline at $0.6 \mathrm{U} / \mathrm{kg} / \mathrm{min}$. Anesthesia was maintained on oxygen and air mixture and inhalational desflurane at 0.5-1 minimum alveolar concentration and IV vecuronium at $0.06 \mathrm{mg} / \mathrm{kg} /$ hour. For cerebral protection, patient was given IV methylprednisolone $1 \mathrm{gm}$ and thiopental sodium of $1 \mathrm{mg} / \mathrm{kg}$. During the surgery, patient was found to have 1.5-2 1 of blood in the pericardium and a rent in the posterolateral wall of the left ventricle with free spurt of blood. Primary closure of the rent was done; bleeding was controlled and closure was done after drain placements. Patient received two pints of blood and two fresh frozen plasmas with 11 of crystalloids intraoperatively with adequate bicarbonate correction on 
the basis of arterial blood gas. Patient was shifted to the intensive care coronary unit for elective ventilation on tapered doses of inotropes. Patient was gradually weaned off the inotropes and ventilatory support over 2 days after adequate correction of hemoglobin and coagulation status and was extubated on day 2 postoperatively, and discharged subsequently.

\section{DISCUSSION}

Balloon mitral valvuloplasty involves an Inoue balloon introduced across the mitral valve via the transseptal or the retrograde route. Inflation of the balloon causes fracture of the valve leaflets at the commissures improving leaflet excursion and orifice area. Complications of BMV (12\%) include severe MR, embolization, cardiac tamponade, interauricular septal defect, acute myocardial infarction, and arrhythmias. The incidence of cardiac tamponade due to perforation is $0.3-0.8 \%$. Perforation could be by the guidewire, dilator, or the septal puncture needle.

Cardiac tamponade is suspected when a still cardiac silhouette, hypotension, and elevated right atrial pressures are noted and can be confirmed by $2 \mathrm{D}$ echo.

Perforations of the right atrial appendage are usually not very severe, and in the majority of cases are resolved with pericardiocentesis and reversal of the anticoagulation. Left ventricular (LV) lacerations, however, result in immediate hemodynamic deterioration and usually require emergency corrective surgery with a very high mortality.

Joseph et $\mathrm{al}^{1}$ in 1997 studied the mechanisms of cardiac perforation in ten cases of cardiac tamponade encountered in a series of $903 \mathrm{BMV}$ procedures. Five of these were due to LV rupture requiring primary repair, out of which one patient developed hypoxic encephalopathy.

Pan et $\mathrm{al}^{2}$ found that 2 of the 8 patients developing cardiac tamponade out of the 300 patients undergoing BMV were due to LV rupture, one of whom died on the procedure table and the other postrepair.

Robertson et $\mathrm{al}^{3}$ in 1990 documented an LV rupture during a BMV with successful surgical repair but a brain dead patient.

Thus, in this very rare complication of BMV, most of these patients require surgical repair and hence general anesthesia, because only partial hemodynamic stabilization can be achieved by pericardiocentesis by a pigtail catheter and autohemoperfusion. The anesthetic considerations for such a complication include:

- Prompt recognition of the complication

- Avoidance of drug-induced myocardial depression

- Maintaining preload and afterload

- Avoiding cerebral hypoxia and residual neurological deficits and

- Maintaining body temperature in bleeding patients with poor cardiac reserve

\section{REFERENCES}

1. Joseph G, Chandy ST, Krishnaswami S, Ravikumar E, Korula RJ. Mechanisms of cardiac perforation leading to tamponade in balloon mitral valvuloplasty. Cathet Cardiovasc Diagn 1997 Oct;42(2):138-146.

2. Pan M, Medina A, Suárez de Lezo J, Hernández E, Romero M, Pavlovic D, Melián F, Segura J, Román M, Montero A, et al. Cardiac tamponade complicating mitral balloon valvuloplasty. Am J Cardiol 1991 Sep15;68(8):802-805.

3. Robertson JM, de Virgilio C, French W, Ruiz C, Nelson RJ. Fatal left ventricular perforation during mitral balloon valvoplasty. Ann Thorac Surg 1990 May;49(5):819-821. 